\title{
Correlation between cup-to-disc ratio and cup/retrobulbar optic nerve diameter proportion assessed by high-resolution ultrasound in glaucomatous eyes
}

\author{
Correlação entre relação escavação/disco e proporção escavação/diâmetro do nervo óptico retrobulbar \\ obtida pela ultrassonografia de alta resolução em olhos com glaucoma
}

Wilian Silva Queiroz ${ }^{1}$, Daniel da Rocha lucena², Juliana de Lucena Martins Ferreira ${ }^{1}$, Maria de Lourdes Veronese Rodrigues ${ }^{1}$, Jayter Silva Paula ${ }^{1}$

\begin{abstract}
Purpose: To investigate the correlation between the measurements of the cup/ retrobulbar optic nerve diameter (C/OND) proportion obtained by high-resolution 20-MHz B-mode ultrasound (US) and those of the cup/disc ratio (C/D) obtained by fundus biomicroscopy (BIO) and optical coherence tomography (OCT).

Methods: Thirty eyes of 15 glaucomatous patients with any C/D proportion were studied. All patients underwent examination of the vertical C/D by BIO with a $78 \mathrm{D}$ lens and time-domain OCT analysis, as well as the vertical C/OND proportion using 20-MHz US measurements. All data were analyzed by correlation and agreement tests.

Results: The Spearman test showed a strong correlation between C/D results obtained by $\mathrm{BIO}$ and the measurements of C/OND (US) ( $r=0.788, p<0.0001)$, and with C/D obtained by OCT $(r=0.8529, p<0.0001)$. However, comparison of C/D results obtained with OCT to those obtained by with C/OND (US) showed only a moderate correlation $(r=0.6727, p<0.0001)$. Bland-Altman analysis did not show good agreement between C/D (BIO) and C/OND (US).

Conclusions: The results demonstrate that B-mode ultrasound examination with a $20 \mathrm{MHz}$ probe can be a good additional method for the evaluation of the C/D ratio in glaucomatous patients, and may be considered as an alternative gross tool in glaucomatous patients with optic media opacities.
\end{abstract}

Keywords: Glaucoma/diagnosis; Optic nerve; Fundus oculi; Ultrasound;Tomography, optical coherence

\section{RESUMO}

Objetivos: Verificar a correlação entre os achados da relação escavação/diâmetro do nervo óptico retrobulbar (E/DNO) obtidos pelo exame de ultrassom (US) modo B de alta resolução com sonda de $20 \mathrm{MHz}$ e a relação escavação/disco (E/D) obtidos pela biomicroscopia de fundo de olho (BIO) e pela tomografia de coerência óptica (OCT). Métodos: Foram analisados 30 olhos de 15 pacientes com diagnóstico de glaucoma com qualquer proporção da relação E/D. Todos os pacientes foram submetidos ao exame de BIO, com lente 78D, e de OCT, com tecnologia de domínio temporal, para a análise da relação E/D vertical e exame de US modo B, Com sonda de $20 \mathrm{MHz}$, para determinação da proporção E/DNO vertical. Todos os resultados foram analisados por métodos de correlação e concordância.

Resultados: Observou-se forte correlação entre as medidas E/D obtidas pela BIO, e as medidas E/DNO (US) $(r=0,788 ; p<0,0001)$, e com as medidas E/D obtidas pelo OCT $(r=0,8529 ; p<0,0001)$. Porém, a análise entre as medidas E/DNO (US) e E/D (OCT) mostrou apenas níveis moderados de correlação $(r=0,6727, p<0,0001)$. O teste de Bland-Altman não mostrou bons níveis de concordância entre E/D (BIO) e E/DNO (US). Conclusões: Os resultados demonstraram que o exame de US modo B com sonda de $20 \mathrm{MHz}$ pode ser um bom método adicional para avaliar a relação E/D de pacientes com glaucoma, a ser considerado como uma ferramenta alternativa na avaliação de pacientes glaucomatosos com opacidades dos meios ópticos.

Descritores: Glaucoma/diagnóstico; Nervo óptico; Fundo de olho; Ultrassonografia; Tomografia de coerência óptica

\section{INTRODUCTION}

The analysis of the optic disc is an important step in the diagnosis of glaucoma and therefore a careful clinical observation should be performed to separate glaucomatous changes from normal data ${ }^{(1-3)}$.

Previous studies have proposed the use of ultrasound examination (US) as an ancillary method for the assessment of glaucoma patients, especially in cases which optic opacity is present ${ }^{(4-6)}$. Although some studies intended to assess blood flow changes in the circulation of the optic disc, focused on the short ciliary arteries, few have attempted to assess the dimensions of the optic nerve cup ${ }^{(7,8)}$, and thus far there is no published study analyzing the cup/retrobulbar optic nerve diameter (C/OND) proportion and comparing the cup/disc ratio (C/D) obtained by ultrasound with those obtained by optical coherence tomography (OCT) in glaucoma.
The objective of the present study was to investigate the correlation between the measures of C/OND proportion obtained by examination with a 20-MHz B-mode ocular ultrasound (US) and those of the C/D ratio obtained by fundus biomicroscopy $(\mathrm{BIO})$ and OCT in glaucomatous patients.

\section{METHODS}

The study was designed as a cross-sectional investigation in which patients were selected from the glaucoma outpatient service of the University Hospital, School of Medicine of Ribeirão Preto, Universidade de São Paulo. The study was approved by the local Research Ethics Committee and was carried out in accordance with the Declarations of Helsinki following good clinical practice guidelines.

\section{Funding: CAPES.}

Disclosure of potential conflicts of interest: W.S.Queiroz, None; D.R.Lucena, None; J.L.M.Ferreira, None; M.L.V.Rodrigues, None; J.S.Paula, None.

Correspondence address: Juliana de Lucena Martins Ferreira. Av. Dom Luís, 1.233 - 14ํandar Fortaleza (CE) - 60160-230 - Brazil - E-mail: julianalmf@yahoo.com.br

Study approved by Research Ethics Committee of HCFMRP-USP - Process\#2603/2008. 
Patients older than 40 years, of both genders, diagnosed with chronic glaucoma of any etiology, with any C/D proportion were screened. The following inclusion criteria were considered: 1 - intraocular pressure greater than $21 \mathrm{mmHg}$, at least three measurements on different days with Goldmann tonometer, with or without antiglaucomatous agents; 2 - typical changes in C/D proportion due to glaucoma (localizing glaucoma signs: Hoyt, notch, asymmetry in the C/D ratio greater than 0.2 , disc hemorrhage, changing the ISNT rule, peripapillary atrophy, acquired pit of the optic nerve, baring of a circumlinear vessel, bayonet vessels, nasalization of vessels, collateral vessels, increased striations of the cribriform lamina, and nasal cupping); 3 - field defects compatible with glaucoma [computerized visual perimetry with the 24-2 Swedish Interactive Threshold Strategy Algorithm (SITA - Standard; Humphrey Visual Field Analyzer 750, Carl Zeiss, Dublin, CA, USA)] reliable and presenting (Hodapp, Parrish, Anderson criteria) ${ }^{(9)}$ three or more adjacent non-edge points with $\mathrm{p}<5 \%$ (on the pattern deviation plot), and one of which depressed at a $p<1 \%$ level; outside normal limits glaucoma hemifield test (GHT); pattern standard deviation (PSD)-level index less than 5\%, in at least one eye. These criteria were considered if they were presented on at least two consecutive visual fields and in combination with the optic nerve changes, previously described.

The following exclusion criteria were considered: optic media opacities; ocular surgeries in the last three months or vitreoretinal surgery at any time; spherical refractive errors greater than $5.0 \mathrm{D}$ or cylindrical refractive errors greater than 3.0 D; vitreoretinal or optic disc malformations; physical or mental disability that prevented the exams, and no consent to participate in the study.

The study included 30 eyes of 15 patients. These eyes underwent a complete ophthalmologic examination (by a single ophthalmologist) including: the best corrected visual acuity, applanation tonometry, and biomicroscopy of the anterior segment. The posterior segment biomicroscopy was performed under mydriasis by two different examiners, in order to evaluate the vertical C/D evaluation [C/D (BIO)]. If no agreement was obtained in each individual C/D evaluation, a third examiner decided the final value. The OCT examination was performed in a similar fashion with the Stratus OCT ${ }^{\mathrm{TM}}$ (Carl Zeiss Meditec, Dublin, CA, USA) on another occasion (without the possibility of subjective comparison with previous annotations of $\mathrm{BIO})$, using the Optic Fast Disc strategy for the determination of the vertical C/D (OCT)

The ultrasonographic evaluation was performed by another ophthalmologist (DR Lucena), with a $20 \mathrm{MHz}$ probe in the B-mode of Vumax $\|^{\text {TM }}$ (Sonomed, NY, USA). The direct contact technique was performed after instillation of a single drop of $0.5 \%$ proxymetacaine and application of $4 \%$ methylcellulose, using an intensity gain of 50 decibels $(\mathrm{dB})$ for optic disc cup diameter $(\mathrm{C})$ and $70 \mathrm{~dB}$ for the diameter of anterior portion of optic nerve (OND). The measurement of the vertical $\mathrm{C}$ was obtained by a cross incidence positioning the probe on the temporal limbus with the probe marker oriented superiorly and the eye in primary gaze position (Figure 1). The axial horizontal incidence was performed to measure the OND, specifically $2.0 \mathrm{~mm}$ posteriorly to the inner surface of the juxtapapillary bulbar wall. In this case, the probe was placed on the cornea and the probe marker was oriented medially, with the patient in maximum abduction gaze position. Patients were asked to move their eyes in all four directions during three minutes in order to induce a redistribution of subarachnoid fluid (to remove subarachnoid fluid and to eliminate the arachnoid surfaces of the optic nerve sheaths) (Figure 2). Finally, a relation between the individual measures, previously recorded in millimeters, of $C$ and OND was obtained and designated as C/OND ratio.

The $\mathrm{BIO}$ C/D ratio, OCT C/D ratio and US C/OND ratio were compared by nonparametric analysis of variance (Kruskal-Wallis test), followed by individual analysis with the Mann-Whitney test. The Spearman correlation test and the Bland-Altman plot analysis were used to study the correlation and agreement between the methods

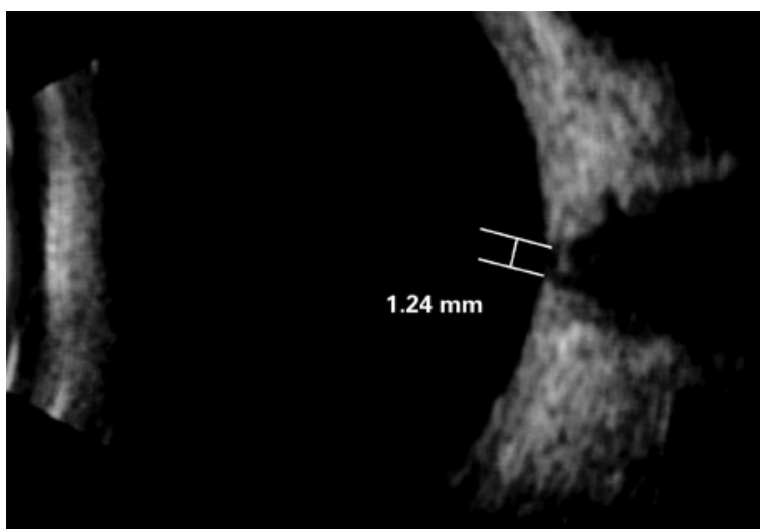

Figure 1. B-mode 20-MHz ultrasound exam showing the measurement of the optic disc cup vertical diameter $(C)$ ( $C$ diameter $=1.24 \mathrm{~mm}$ ); with the probe positioned in the temporal limbus and the eye in primary gaze position.

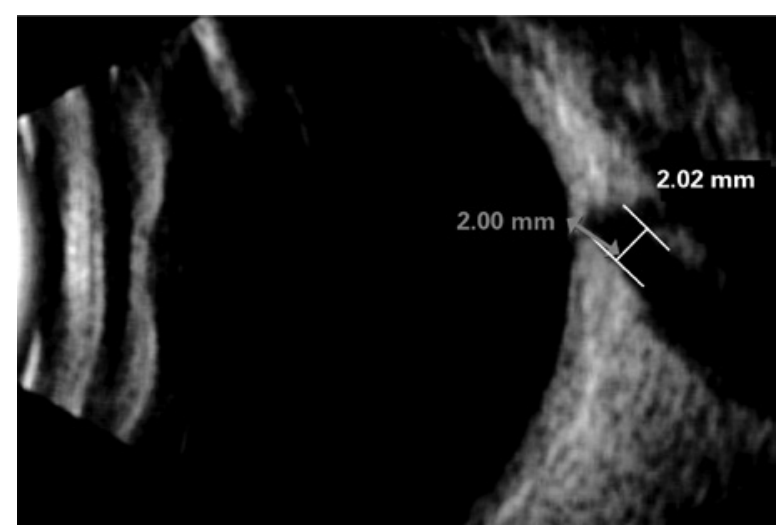

Figure 2. B-mode20-MHzultrasound exam showing themeasurement of the retrobulbar optic nerve diameter (OND - white line $=2.02 \mathrm{~mm}$ ) taken $2.0 \mathrm{~mm}$ posteriorly to the inner surface of the juxtapapillary bulbar wall (gray arrow), using an axial horizontal incidence.

(GraphPad Prism 5.0a; GraphPad Software Inc., CA, USA). The generalized estimating equations were also used in order to account for potential correlation between eyes'data (IBM SPSS Statistics 21.0, Illinois, USA). P-values less than 0.05 were considered statistically significant.

\section{RESULTS}

Of the 15 subjects (30 eyes) evaluated, nine were females and six were males. The median age was 58 years (range: 46 to 72 years).

All subjects tested presented visual acuity of 0.3 logMAR or better. The mean vertical C/D obtained by the $\mathrm{BIO}$ was 0.7 (range: 0.3 to 1.0 ) and that obtained by the OCT was 0.72 (range: 0.32 to 1.00). In the measurements performed with the US, the mean size of the vertical cup was $1.25 \mathrm{~mm}$ (range: 0.6 to $1.6 \mathrm{~mm}$ ), and the retrobulbar optic nerve diameter was $2.88 \mathrm{~mm}$ (range: 2.5 to $3.1 \mathrm{~mm}$ ), leading to a mean C/OND proportion of 0.44 (range: 0.20 to 0.57 ).

Comparison between the means of the cup relations revealed statistically significant differences among the three forms of analysis performed [C/D (BIO); C/D (OCT) and C/OND (US)] by the Kruskal Wallis test ( $p<0.0001$ - Figure 3$)$. After individual comparisons, no statistically significant difference was observed only between C/D (BIO) and $C / D(O C T)$ by the Mann-Whitney test $(p=0.818)$.

After analysis of the C/D (BIO) and C/D (OCT) variables by the Spearman test, we observed a strong correlation (Spearman correlation coefficient $r=0.8529, p<0.0001$ ) between the measurements performed (Figure 4). 
The measures observed by US were also analyzed with the Spearman test $(r=0.800, p<0.0001)$ and correlated with $\mathrm{BIO}$ and OCT. A strong correlation was identified between direct measurements of the vertical cup of the optic disc by US and those of the C/D ratio given by $\mathrm{BIO}$ (Figure 5). As seen in figure 6, the values of the C/OND (US) ratio also showed a strong correlation (Spearman $r=0.788, p<0.0001$ ) with the $C / D(B I O)$ ratio.

In figure 7, the lowest correlations were observed for the C/OND (US) ratio and C/D (OCT) ratio, which showed moderate correlation by Spearman's coefficient $(r=0.6727, p<0.0001)$. None of analysis described above presented different results in terms of significance level after statistical correction for potential inter-dependence findings between eyes of the same subject (GEE).

Using Bland-Altman plot analysis, a poor agreement was observed between US and BIO values (mean difference of readings equal to 0.26 , with a standard deviation of 0.11 ). It is noteworthy that a better agreement was demonstrated for measures with mean C/D ratios under 0.4 (Figure 8).

\section{DISCUSSION}

Using the B-scan, Winder \& Atta (1996) noted that only cups 0.5 $\mathrm{mm}$ or more in diameter could be detected by the method, and that a C/D ratio directly measured in the optic disc topography could lead to an error. However, they noted that the probe used could be the cause of the inability to obtain the desired accuracy ${ }^{(5)}$. In the present study, the echographic evaluation was performed with a $20 \mathrm{MHz}$ highresolution probe and the procedure showed a strong correlation with C/D (BIO) measures both in terms of the C/OND (US) ratio and the direct measurement of the optic nerve cup.

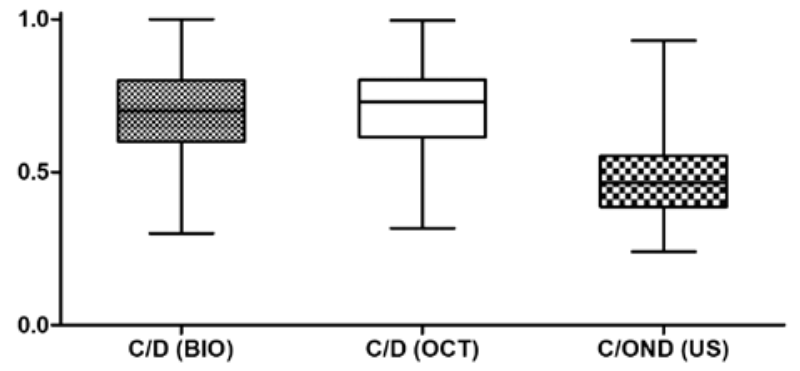

Figure 3. Distribution of the relation values between the cup and the optic nerve (C/D and $\mathrm{C} / \mathrm{OND}$ ), obtained with fundus biomicroscopy (BIO), optical coherence tomography (OCT) and ultrasound (US).

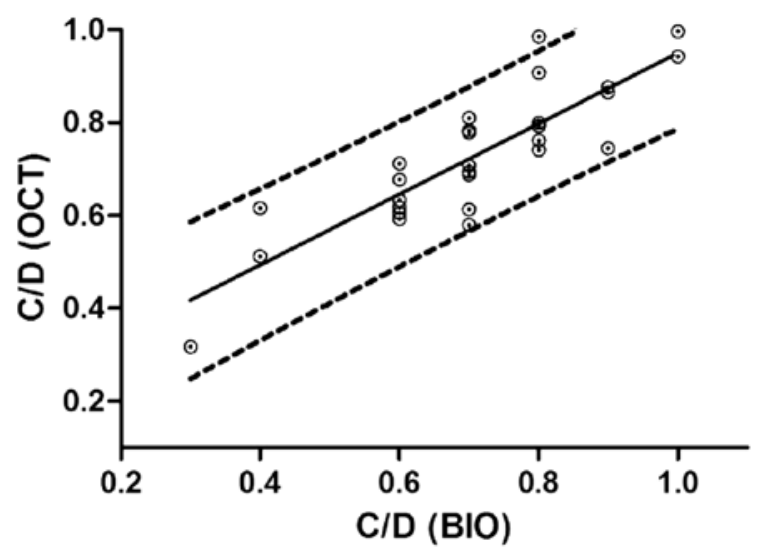

Figure 4. Correlation between the cup/disc (C/D) values obtained by fundus biomicroscopy (BIO) and optical coherence tomography (OCT).
Previous investigations have shown that in glaucomatous patients the thickness of the retrobulbar optic nerve decreases with disease progression, a fact that would likely lead to a better correlation with the C/OND (US) proportion ${ }^{(10-12)}$. With the evolution of the disease, an increase in the C/D ratio would be assumed to occur possibly due to the shrinking thickness of the retrobulbar optic nerve

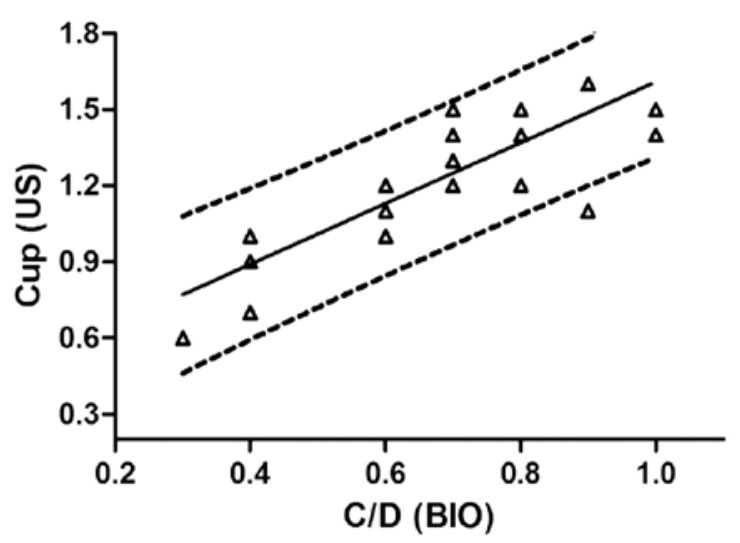

Figure 5. Correlation between the vertical cup values of the disc (D) obtained with ultrasound [cup (US)] and the cup/disc (C/D) ratio of the fundus biomicroscopy (BIO).

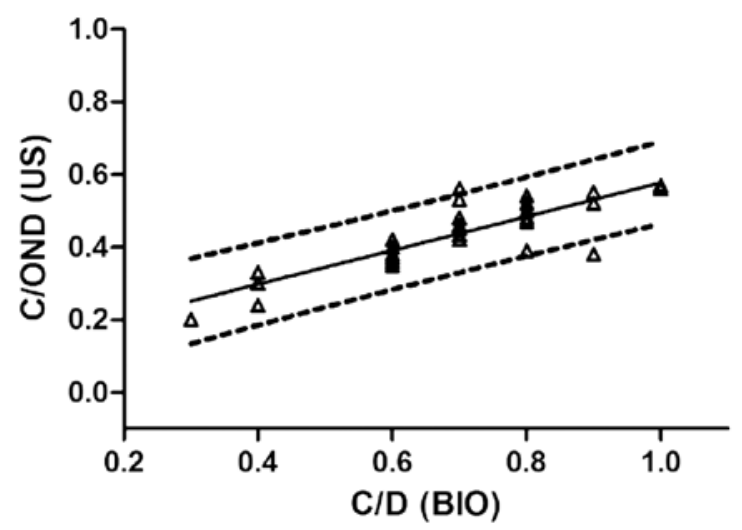

Figure 6. Correlation between the cup/retrobulbar optic nerve diameter (C/OND) values obtained with ultrasound (US) and the cup/disc (C/D) ratio of the fundus biomicroscopy (BIO).

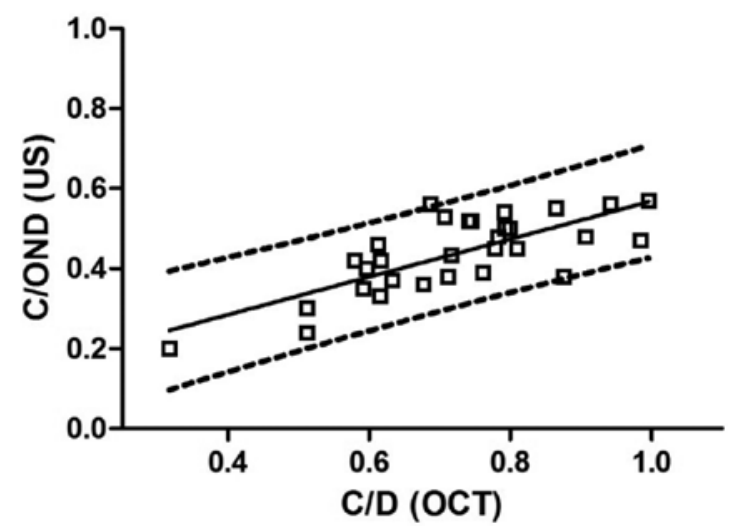

Figure 7. Correlation between the cup/retrobulbar optic nerve diameter (C/OND) values obtained with ultrasound (US) and the cup/disc (C/D) ratio obtained using optical coherence tomography (OCT). 


\section{Bland Altman}

Mean and $1,96 \times S D$

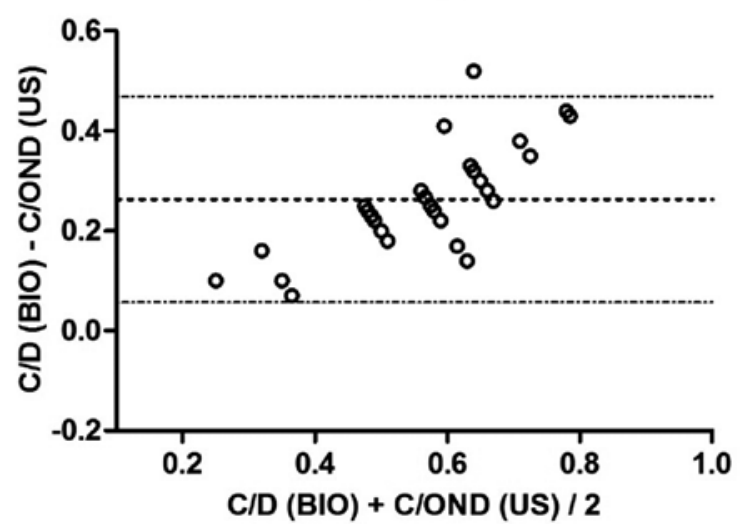

Figure 8. Bland-Altman plot of results of vertical cup/disc ratio obtained with biomicroscopy $[C / D(B I O)]$ and the C/OND ratio obtained with ultrasound. Each point is represented on the graph by assigning the mean of these two variables as the abscissa value, and the difference between them as the ordinate value. Please consider main text for detailed explanation regarding C/OND ratio calculation. [ $\pm 1.96 \mathrm{x}$ standard deviation plot as limits of agreement].

(denominator), resulting in a proportion that would vary in a more sensitive fashion than the simple C/D ratio. Based on this assumption, our purpose was to emphasize the use of such proportion based on a still unpublished ultrasonographic analysis of the C/OND, since previous studies have assayed the C/D ratio and the retrobulbar optic nerve diameter, but have not analyzed the C/OND proportion ${ }^{(10,13)}$.

Although a good correlation was demonstrated, a poor agreement was observed between C/OND (US) and C/D (BIO) measures. It could be an expected result since different devices were used to determine these ratios, especially because C/OND (US) had the measurements of the retrobulbar diameter as denominator, which was not considered for the C/D (BIO) determination. In fact, Bland-Altman dispersion plot analysis displayed a wide limit of agreement, although a better agreement could be seen for low C/D values $(<0.4)$. Previous studies discussed discrepant findings, with better correlation for higher C/D values ${ }^{(4,5)}$, however different devices and approaches were used. Disregarding the potential bias related to the small number of subjects and differences between examiners in each study, we speculate that less damaged optic nerves could provide a better discrimination of US images of both the cup and the retrobulbar portion.

To best of our knowledge, no previous direct comparisons between OCT and echographic measurements of the optic nerve cup have been reported, and a previously published study used another tool, such as Heidelberg Retinal Tomography $(\mathrm{HRT})^{(4)}$. In the present study, a high correlation was observed between $\mathrm{BIO}$ data and OCT data, which indicates the quality of the procedures and agrees with some studies that compared fundus photographs with $\mathrm{OCT}^{(14-16)}$. Yet, the C/D (OCT) measures showed only a moderate correlation with the C/OND (US) ratio.

Some potential biases of this research could be addressed as follows: 1) absence of a control group, although the objective of this study did not include diagnostic features and therefore it such group would not be required; 2 ) the evaluation of the optic disc diameter restricted to the vertical scan - the absence of analyses of horizontal scans could endanger the conclusions since different cup size and shape could interfere with the results obtained from the correlation tests; and 3) unlike HRT, the OCT (fastscan protocol) analyzes the topography of the optic nerve based on the scanning of only six intersecting lines and, therefore, is amenable to several analysis issues.
To minimize such OCT-related problems, the examiner did not make adjustments of the reference points of the vertical line-scanning device and, when he noticed large analysis discrepancies, the test was repeated or disregarded.

Even considering both limitations and poor agreement, this study presented a new approach to the evaluation of the C/D proportion using BIO and OCT as standard examinations, which could be useful for glaucomatous patients with no possibility of fundus examination. Further studies are needed to confirm or even enhance these findings.

\section{CONCLUSION}

The present study demonstrated that the vertical C/OND proportion obtained by B-mode ultrasound examination with a $20 \mathrm{MHz}$ probe showed strong correlation, despite a low agreement, with C/D values obtained by both $\mathrm{BIO}$ and OCT. The determination of this proportion, as described here, could be an alternative method for assessing the C/D ratio in glaucomatous eyes, mainly to be used in patients with optic media opacities.

\section{REFERENCES}

1. Foster PJ, Buhrmann R, Quigley HA, Johnson GJ. The definition and classification of glaucoma in prevalence surveys. Br J Ophthalmol. 2002;86(2):238-42. Review.

2. Lin SC, Singh K, Jampel HD, Hodapp EA, Smith SD, Francis BA, Dueker DK, Fechtner RD, Samples JS, Schuman JS, Minckler DS; American Academy of Ophthalmology; Ophthalmic Technology Assessment Committee Glaucoma Panel. Optic nerve head and retinal nerve fiber layer analysis: a report by the American Academy of Ophthalmology. Ophthalmology. 2007;114(10):1937-49. Erratum in Ophthalmology. 2008;115(3):472. Comment in Ophthalmology. 2008;115(7):1266-7; author reply 1267-8.

3. Barbosa CP, Angelini PF, Schor P, Paranhos Junior A. Simulated cup/disc ratio: a tool for ophthalmologists. Arq Bras Oftalmol. 2010;73(4):320-2.

4. Beatty S, Good PA, McLaughlin J, Tsaloumas M, O'Neill EC. Evaluation of optic disc cupping using high-resolution ocular ultrasound. Eye (Lond). 1998;12(Pt 1):54-60

5. Winder S, Atta HR. Ultrasonography of the optic disc cup in discs of various sizes. Eye (Lond). 1996;10(Pt 6):732-6.

6. Darnley-Fisch DA, Byrne SF, Hughes JR, Parrish RK $2^{\text {nd }}$, Feuer WJ. Contact B-scan echography in the assessment of optic nerve cupping. Am J Ophthalmol. 1990;109(1): 55-61.

7. Findl O, Strenn K, Wolzt M, Menapace R, Vass C, Eichler HG, et al. Effects of changes in intraocular pressure on human ocular haemodynamics. Curr Eye Res. 1997; 16(10):1024-9.

8. Nicolela MT, Walman BE, Buckley AR, Drance SM. Various glaucomatous optic nerve appearances. A color Doppler imaging study of retrobulbar circulation. Ophthalmology. 1996;103(10):1670-9.

9. Hodapp E, Parrish RK II, Anderson DR. Clinical decisions in glaucoma. St Louis: The CV Mosby Co; 1993. p.52-61.

10. Dichtl A, Jonas JB. Echographic measurement of optic nerve thickness correlated with neuroretinal rim area and visual field defect in glaucoma. Am J Ophthalmol. 1996; 122(4):514-9.

11. Jonas JB, Schmidt AM, Müller-Bergh JA, Naumann GO. Optic nerve fiber count and diameter of the retrobulbar optic nerve in normal and glaucomatous eyes. Graefes Arch Clin Exp Ophthalmol. 1995;233(7):421-4.

12. Lagrèze WA, Gaggl M, Weigel M, Schulte-Mönting J, Bühler A, Bach M, et al. Retrobulbar optic nerve diameter measured by high-speed magnetic resonance imaging as a biomarker for axonal loss in glaucomatous optic atrophy. Invest Ophthalmol Vis Sci. 2009;50(9):4223-8.

13. Beatty S, Good PA, McLaughlin J, O'Neill EC. Echographic measurements of the retrobulbar optic nerve in normal and glaucomatous eyes. Br J Ophthalmol. 1998; 82(1):43-7.

14. Neubauer AS, Krieglstein TR, Chryssafis C, Thiel M, Kampik A. Comparison of optical coherence tomography and fundus photography for measuring the optic disc size. Ophthalmic Physiol Opt. 2006;26(1):13-8.

15. Samarawickrama C, Pai A, Huynh SC, Burlutsky G, Jonas JB, Mitchell P. Measurement of optic nerve head parameters: comparison of optical coherence tomography with digital planimetry. J Glaucoma. 2009;18(8):571-5.

16. Kotera $Y$, Yasuno $Y$, Hangai M, Inoue R, Makita S, Nakanishi H, et al. Comparison of spectral domain optical coherence tomography and color photographic imaging of the optic nerve head in management of glaucoma. Ophthalmic Surg Lasers Imaging. 2009;40(3):255-63. 